\title{
Arrival City: Refugees in three German cities
}

\author{
Hajo Neis, Briana Meier, Tomoki Furukawazono \\ Department of Architecture, Portland Urban Architecture Research Laboratory PUARL, \\ University of Oregon, Portland, OR, USA \\ E-mail: hajoneis@uoregon.edu,meier@uoregon.edu,tomokif@uoregon.edu
}

Dedicated to Tahir from Pakistan

\begin{abstract}
Since late 2015, the authors have studied the refugee crisis in Europe and the Middle East (PUARL Refugee Research Website, 2017). In this paper, we present three case studies in three different cities in Germany. Refugees are everywhere in Germany, even in smaller towns and villages. The case study cities are at different scales and include Borken (15,000 people), Kassel, a mid-size city (200,000), and Essen, a larger city $(600,000)$ which is part of the still larger Ruhr Area Megacity. In these cities we try to understand the life of refugees from their original escape city and country to their arrival in these new communities. Our work focuses on the social-spatial aspects of refugee experiences, and the impacts on urban morphology and building typology. We also try to understand how refugees manage their new life in partial safety of place, shelter, food and financial support, but also in uncertainty and insecurity until officially accepted as refugees. Beyond crisis, we are looking at how refugees can and will try to integrate into their host countries, cities, and neighborhoods and start a new life. Urban architecture projects for housing and work opportunities that help the process of integration are part of this study. Particularly, in this paper, we investigate the reality on the ground of the positive Wilkommen Kultur (welcome culture) and the high expectations and implied promises that were set in 2015 by Chancellor Angela Merkel and German society.
\end{abstract}

Keywords: Arrival City, Refugees, Urban Morphology, Design and Building Projects.

\section{The Wilkommen Kultur (welcome culture) and its implied promises}

The United Nations estimates that there are about 250 million migrants in the world, of which more than 65 million people are refugees (United Nations, 2015). This means that one in every 113 people alive today are now displaced by war, violence, and persecution (UNHCR, 2017). Refugee arrivals in Europe continue at crisis levels, particularly in Germany, where more than 435,000 asylum seekers arrived in the first half of 2016 alone (UNHCR, 2016). These forced migrants joined the nearly one million earlier arrivals to Germany in 2015, most still in limbo awaiting asylum approval or appeals. In Europe and in the United States, migration issues are divisive and at the fore of public debate and protest. How the world responds to this global crisis will arguably impact the trajectory of peace and well-being on this planet for generations to come.

In 2015, in response to the ongoing conflict and humanitarian crisis in Syria, German Chancellor Angela Merkel welcomed refugees into Germany with a wide open door to help them in a direct and humanistic way. At the time she calmed down the concerns of the German people with the now famous expression "Wir schaffen das schon" "We will manage that") (Sommerpressekonferenz von Bundeskanzlerin Merkel, 2015). 
Merkel's "Wilkommen" (welcome) policy has generated a large number of positive reactions and activities in Germany at all administrative levels of federal, state, county, and municipality, as well as an overall positive response by civil society with its social, religious, and private associations and organizations, and individual citizens. Initially, a Wilkommen Kultur (welcome culture) emerged in communities throughout Germany. German communities took on the role of "arrival city" (Saunders, 2012), and collectively generated an atmosphere of "making Heimat" ("Heimat" is a German term that means to create a place for one's own life, feeling, wellbeing, and belonging, embedded in the history and community to which one belongs) (Schmal, Elser, Scheuermann, 2016). Help and support continues today in a pragmatic fashion after two years of up and down experiences.

The Portland Urban Architecture Research Lab (PUARL) has begun initial, preliminary research by developing a set of focal areas situated within the broader context of this international crisis. These focal topics are also referred to as building blocks within this larger study of refugee escape, assimilation, integration, and return to original home country. Current building blocks that are being studied include: urban morphology studies, building and typological studies, refugee legal frameworks, patterns and pattern languages for assimilation and integration of refugees, project languages for particular design and building projects, and lastly, case studies of cities towns and neighborhoods, the first of which are presented here. Initial versions of this research were presented at the International PUARL Conference in San Francisco in October 2016. (PUARL International Conference, 2016)

In this paper we investigate the reality of this positive Wilkommen Kultur and the high expectations and implied promises that were set in 2015 by Angela Merkel and German society. Our discussion and findings are drawn from research conducted by the authors in Germany in August 2016, as well as preliminary visits undertaken by Dr. Hajo Neis in December 2015 and March 2016, and a follow-up visit in December 2016. Our research focuses on the ways in which the invitation for refugees to come to Germany is playing out in these three communities in regard to primary immediate needs for refugees, and in regard to the initial impacts on the German citizens and socialspatial aspects of German communities. In this paper, we analyze how the Wilkommen Kultur is actually working on the ground in states, cities, towns, and villages. To this end, we selected three German cities that serve as case studies with which to address our main question: the small town of Borken in the state of Hessen, the larger city and county of Kassel, and the much larger city of Essen, a part of the Ruhr Area Megacity of five million people.

Our initial research included informal interviews with German officials at various levels. Given Dr. Neis's German citizenship and wide network of contacts in Germany, we were also able to interview a number of German citizens working in the private and volunteer sectors, as well as university faculty. Professor Alexander Schmidt and doctoral candidates at the University of Duisburg Essen provided numerous interviews and tours of refugee facilities in Essen, and they also shared the final report from a masters' degree planning seminar (Wehling, Schmidt, Pozo, Casanova, Pahlen, and Kürzdörfer, 2015). We also spoke informally with numerous refugees at various camps and group housing facilities, and we met with a few Syrian refugees for detailed interviews. However, we note that this first round of case study research was an initial investigation, and our evaluations are suggestive, rather than exhaustive.

In the following sections, we provide a series of short vignettes and brief discussions that illustrate how these three communities are working to address the more immediate, basic needs of refugees. Specifically, we examine the following: a. overall support structure, b. housing, c. communication and acclimatization, d. work, and e. the formal, legal asylum application process. We end the paper with a series of initial findings and evaluations of the current situation, and a brief discussion on the outlook for the near term future of refugee integration in Germany. 
Asyl-Unterkünfte in Essen

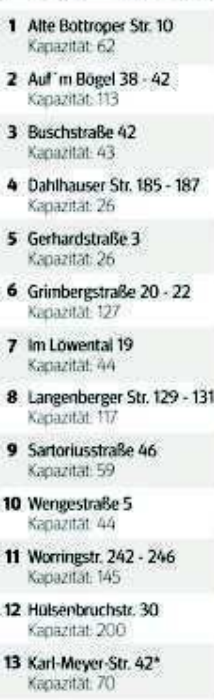

Karl-Meyer-Str. 42

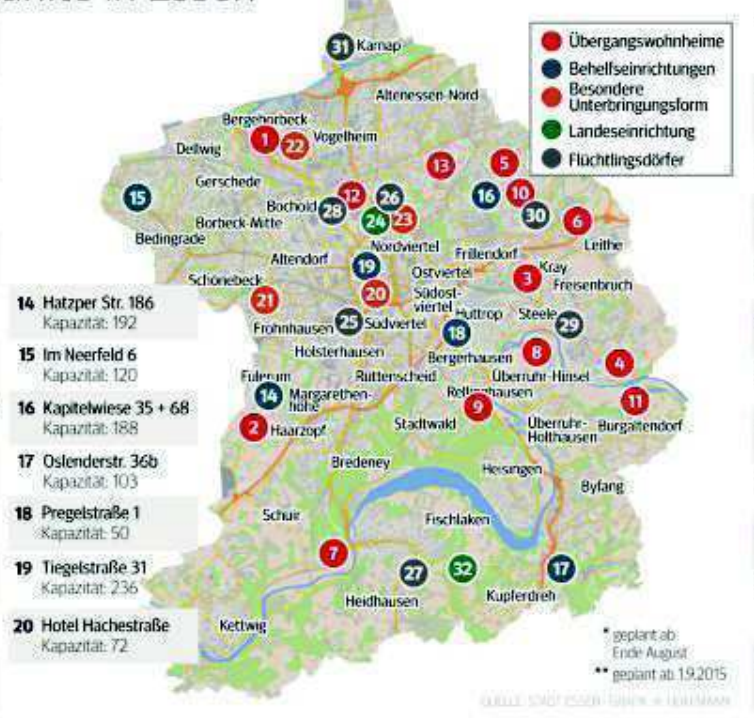

Figure 1.

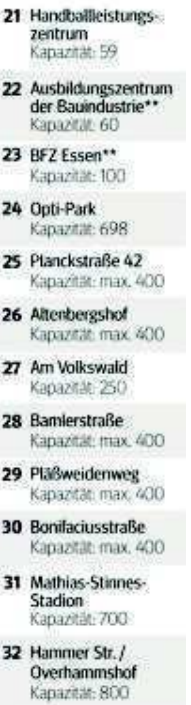

Map with different kinds of shelters and camps for refugees in use in the city of Essen in 2015-2016 (Source: Der Westen, 2015).

\section{Detailed topics of investigation in the Arrival City}

Help and support structure in cities, towns and villages, counties, states, and the country

The most amazing reality for people who come from outside the country and visit Germany to observe the refugee situation is the fact that refugees are present everywhere, including in very small villages and towns, such as the interim housing in a former hotel near Dr. Hajo Neis' house in the small town of Borken. Germany has adopted a policy of distributing refugees to communities throughout the country according to the so-called "Königstein Key," which sets quotas for each state according to economic capacity (BAMF Glossary, 2017). Distribution is roughly organized in three to four levels of helping and administering refugees. At the federal level refugees are first registered, and then they are distributed to the different states. The state government then continues to distribute refugees to counties, cities, towns, and villages. After their initial placements by the government, refugees' daily life becomes a purely local event in which refugees and citizens of the towns, villages, and neighborhoods have to exist together.

It is worthwhile to emphasize that the administrative structure could not handle all these refugees through the government alone. In Germany, a well-functioning social structure has been very helpful. In addition to the city administration, religious organizations, and a number of volunteers and partially paid helpers, there is a very strong structure of 'Vereine,' which are associations for all kinds of purposes from sports clubs to historical associations, garden associations, and even rabbit clubs. In Germany one can find anything under the sun for which people might create associations. These associations tend to be extremely helpful in supporting refugees in various ways. For example, sports clubs fulfill a key role in helping young male refugees to engage their energy.

Refugee housing in Essen, Kassel, and Borken

As in much of Germany, the number of refugee arrivals in Essen in 2015 and 2016 surpassed the amount of available built spaces in which to house refugees even temporarily. During the height of refugee arrivals from 2015 to end of 2016, the City of Essen operated thirtytwo temporary facilities throughout the city (Figure 1). Due to the large number of arrivals in 2015, Essen, like other places in Germany, moved to a system of modern tent camps in 


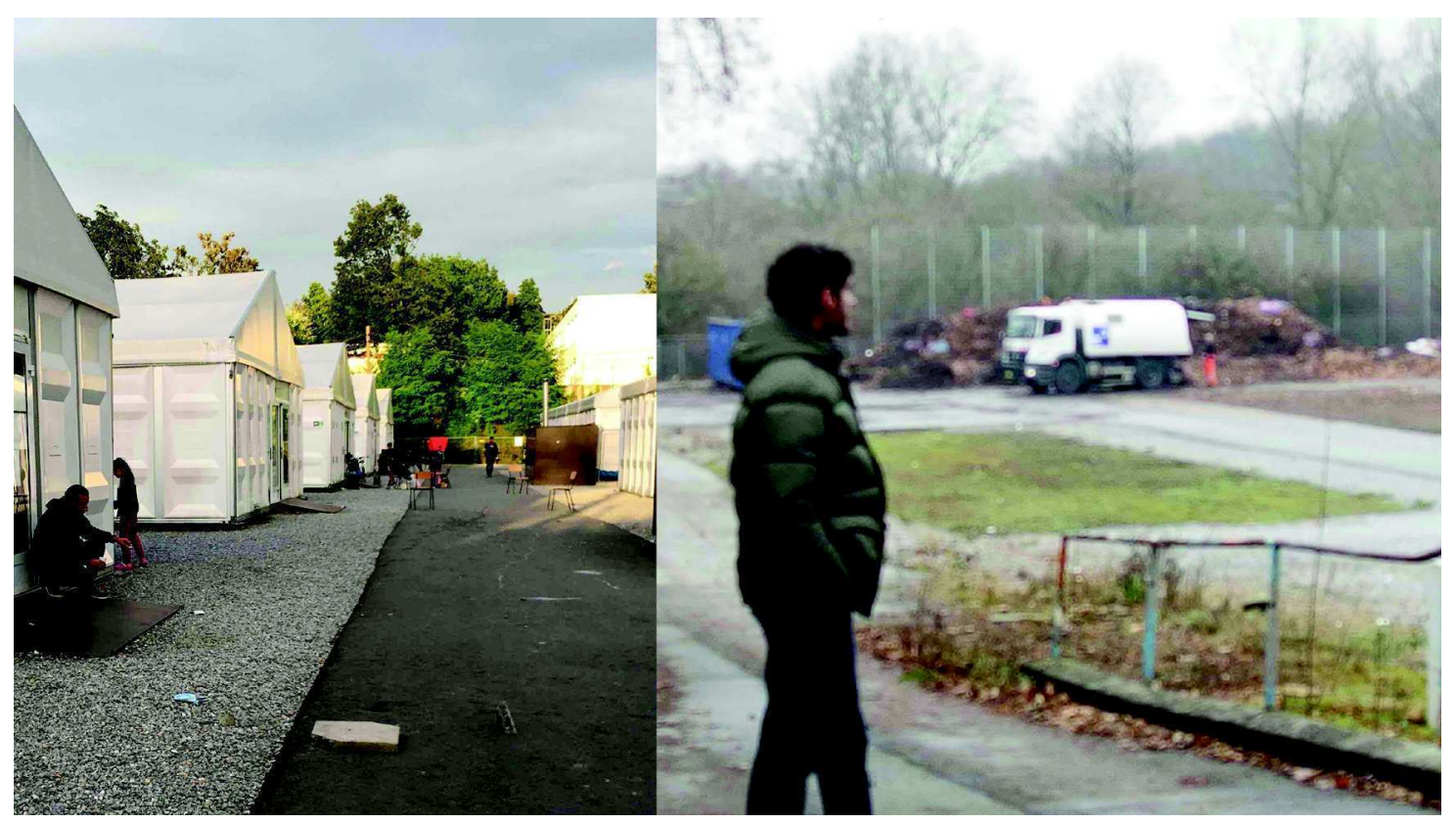

Figure 2.

a. Temporary tent camp structure in Altenbergshof, Essen, in use in 2015, and b. after removal one year later in 2016. With researcher Aurelio David from University Duisburg-Essen.

order to provide basic shelter for new arrivals. Other permanent structures, such as hostels, hotels, and empty buildings, were retrofitted for temporary refugee housing. In contrast to Landkreis Kassel, where the Landkreis (county) oversees and manages all aspects of refugee support, in Essen, management of the tent camps has been contracted out to a private firm, European Home Care (EHC). EHC managed all aspects of the temporary housing, including distribution, operations, meals, and security.

By the end of 2016, most of these temporary camps had been closed and refugees had moved to other temporary accommodations, but this time in permanent structures. During a visit in December 2016, Dr. Neis was indeed surprised that some of the camps we had visited in August 2016 were non-existent after a year of use. In December 2016, Dr. Neis visited two of these camps - Altenbergshof and Bamlerstrasse - and only found the paved floor plan remnants formerly occupied by tents and paths, with gravel still in place (Figure 2). The question of course is where the refugees were moved to, in what kind of housing, and what kind of building structures, old and run down or remodeled and new. We were told by university researchers that refugees from one camp were partially moved to the city's edge with poor transport connections.

Essen is now working with a challenging situation of accommodating these thousands of new arrivals in their own housing stock in a city with very low vacancy rates for apartments (only 3\% according to the City) (Essen City Website, 2017a). The City places refugees whose asylum has been approved in their own apartments, but asylum approval can take months or even longer than a year. In addition, the City advertises for volunteer landlords to rent to refugees. Refugees are also eligible to find their own apartments after achieving refugee status, but in the meantime, they most often live in dormitory style housing with others from around the world.

During the past three years, the City of Essen, like any other city in Germany, has had to work with constantly changing forecasts for the number of refugees who will arrive. Recently, arrival rates have slowed substantially and plans to build additional dormitory style facilities or to retrofit existing buildings have been canceled. In the meantime, the City is still working to find apartment placements and to manage the facilities and needs of thousands still housed in dormitory style facilities.

In the town of Borken with about 13,500 


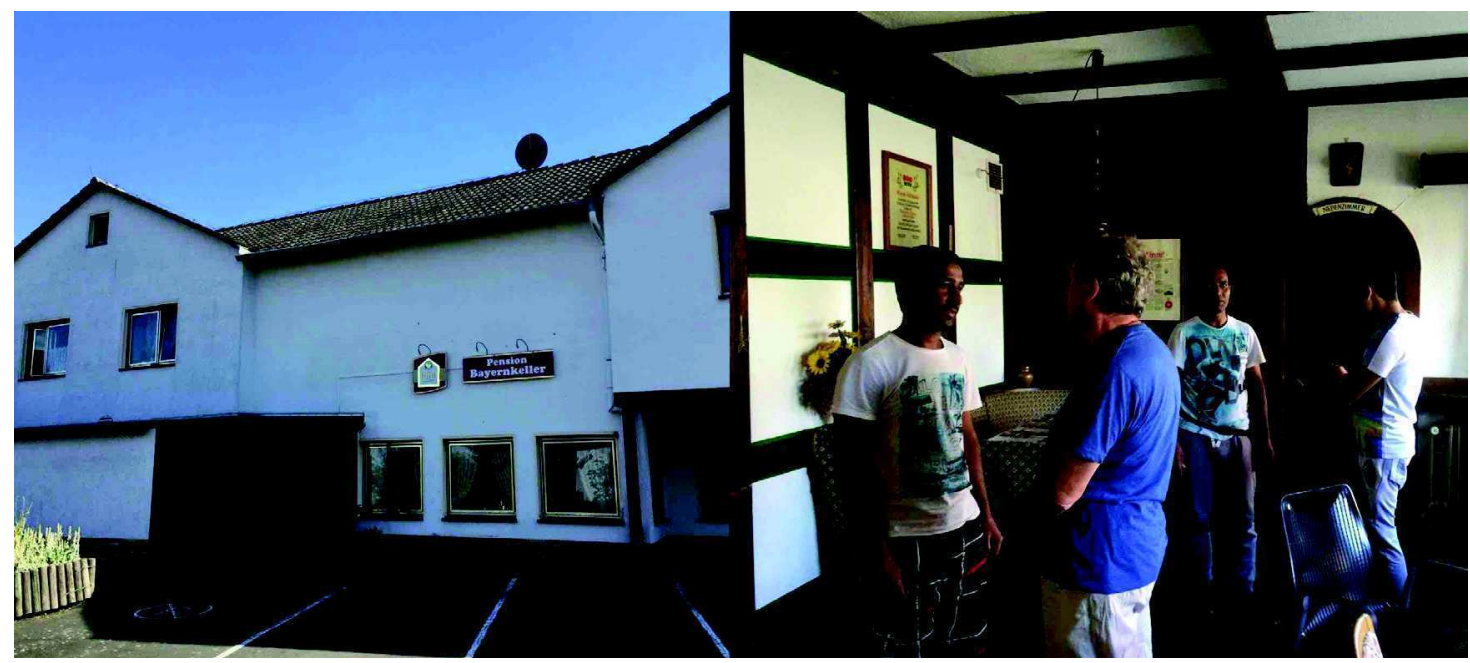

Figure 3.

a. The restaurant and hotel 'Bayernkeller' used for refugee housing in the town of Borken, and b. conversation with refugees inside the hotel in 2016. Dr. Neis with Tahir from Pakistan.

inhabitants and about 200 refugees (number changes all the time because of new arrivals), refugees are located in the core town but also in neighboring villages that are part of the municipality. Most of the young male population lives in the core town in a former restaurant with hotel, called Bayernkeller (Illustration 3). In the village of Kleinenenglis, a number of families are housed in a four story apartment building, and in the village of Gombeth, a former community building now serves as a shelter for unaccompanied minors. Distributed in some former prefabricated 'Plattenbauten,' a few refugee families live in individual apartments rented by the City.

Acclimatization, assimilation, communication, and living in a new local culture

After going through the federal arrival camps in a new country, then passing through the state arrival camps, refugees finally reach the local city, town or village arrival places, where they will live for quite a while and get used to local life and culture to reach their main objective of getting safe asylum status.

In practical terms, all refugees are taken care of by the government according to European Union regulations and the German Constitution. Upon arrival in Germany, all refugees are provided shelter in some form. They each receive Euro 359 for their personal use and expenses, and they are taken care of by a number of institutions, as well as private helpers and volunteers (Reddit, 2017). They have arrived in a place where some fundamental life necessities are provided for them, at least for a while.

Refugees also face a number of challenges that will take time and real effort to live up to. They are first faced with communication issues, the problem of learning a new language, the problem of learning new customs, getting used to living in a European culture, getting around in a new place and neighborhood, needing help with all kinds of paper work, and dealing with trauma from experiences in conflict zones and serious problems on their escape route from their original home to a new arrival city in a different country, language, and culture.

There are also events of coming together and just enjoying a moment of relief and understanding each other. On Christmas in December of 2015, the Protestant Church in Borken organized a live music event with modern music within the church as part of its ecumenical ongoing efforts, and all refugees were invited. Dr. Neis attended and experienced local residents and Islamic women, children, and some young men coming together to participate, clap, and sing to modern mixed music in a Protestant church. In particular, small children running around with happy red faces made one think quite positively about the future of living together.

Language skills are critically important to 


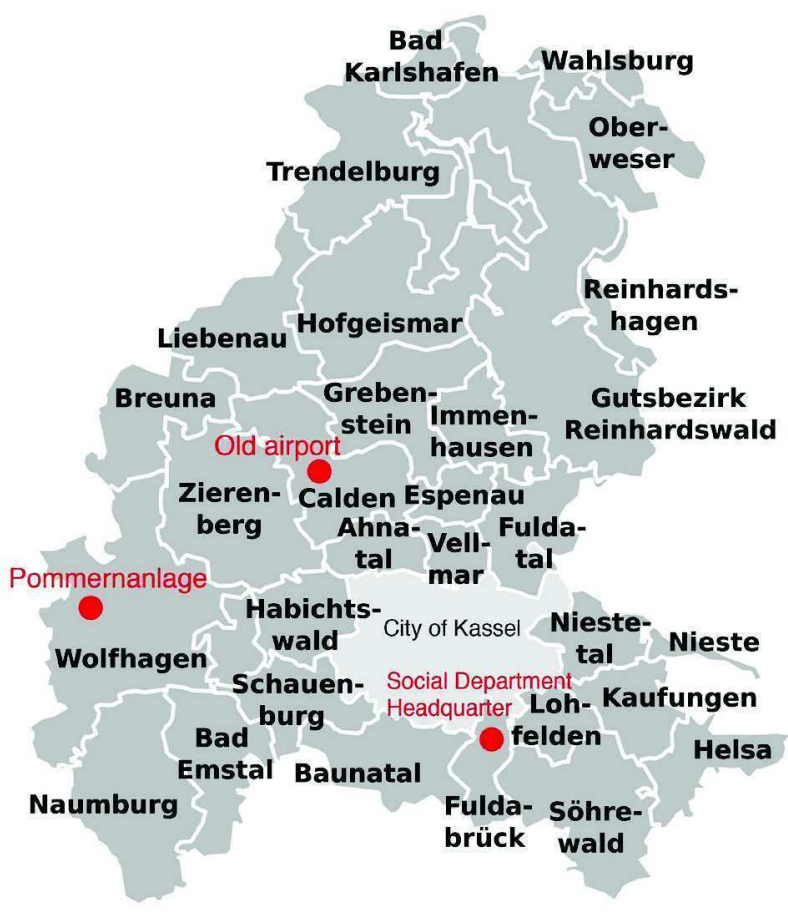

Figure 4.

Map of county of Kassel with various individual municipalities and locations, including the city of Wolfhagen with the Pommernanlage, the old airport buildings in the municipality of Calden as a federal refugee camp, and the main Social Department Headquarters location in Kassel.

interactions, municipal buses service the Pommernanlage with regular stops between the camp and the town. Language classes are typically offered in town to encourage people to mix outside of the camp and to become part of the community. Ms. Elena Beck, a social worker at the camp, explained to Briana Meier the importance of these informal programs in helping refugees and Germans interact and connect:

"It is important not to make a parallel world here in the camp. It is important for people to have structure and purpose, and to feel that they have some involvement. That is why there are no groceries here (at the camp), and why the German course is offered in town." (Figures 4 and 5)

In Essen, language classes are also provided by various charities and volunteer groups, such as the Diakonisches Hilfswerk. Classes offered in various parts of the city provide refugees a chance to get out of the camps or refugee-only facilities. During a conversation with

supporteven themostbasic interactions between refugees and locals in host communities, and these skills are also key to opening possibilities for employment in the host country. In 2015 and 2016, during the height of refugee arrivals, government emphasis understandably focused first on meeting basic needs of safety, housing, food, clothing, etc. Work placement efforts and language training then developed in various forms according to the capacities and motivations of various government institutions, but with language training in particular, much of the municipalities efforts are well supported by the private sector through charities and informal volunteer programs.

For instance, in the town of Wolfhagen, part of the county of Kassel, retired people, particularly former school teachers, were eager to put their skills to work and so started up a variety of German language classes for the refugees at the Pommernanlage facility near the town, formerly used as a military camp. As a way of further encouraging everyday
Briana Meier and Tomo Furukawazono in the private flat he had recently rented, Assaad, a refugee from Syria, explained that although the German lessons were critical for him in learning the basics of the language, the way he really learned to converse was through actual informal conversations with Germans, such as those he had while volunteering at a clothing donation center:

"The most important thing is to help people get better integrated. For example, to learn a language, people need to speak it, not just have lessons then go back to the camp. We got so much contact with German people through working together at the Kleider Kammer. We succeed in language without going to any school by practicing the language with our friends."

Work and work-learning related activities

If there are any two major issues for refugees of importance it is housing and work, Mr. 


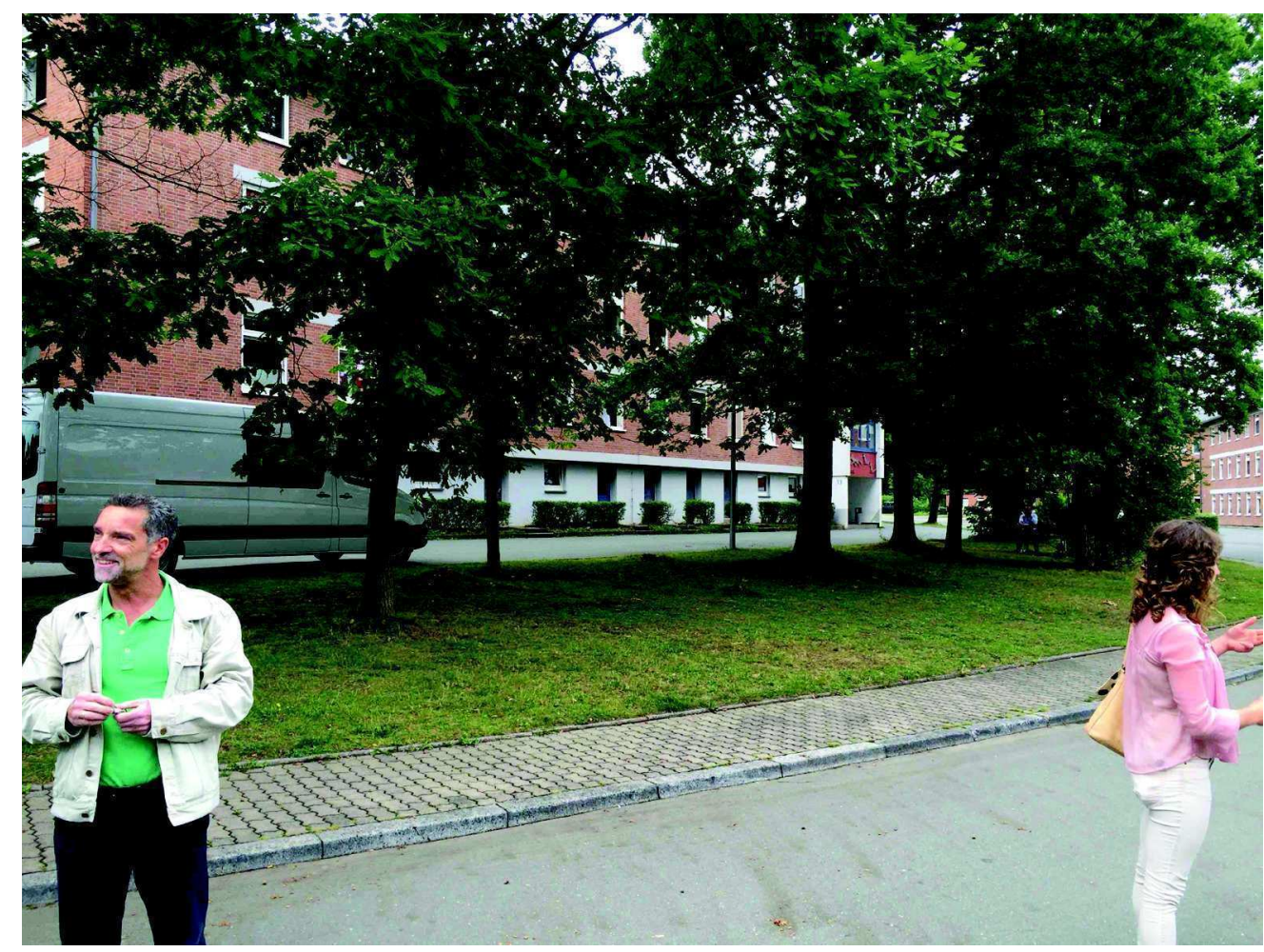

Figure 5.

Pommernanlage - Social workers Mr. Zeuch and Ms. Beck at a former military barracks for a tank battalion in the town of Wolfhagen, now used as a peaceful camp for refugee.

Rossberg, head of the County of Kassel refugee organization and department of social affairs, easily assured us. While housing is part of the refugee package according to German laws, work is less easily available and sanctioned (more in Finding 5 about the legal structure of work). Still, there are kinds of work that refugees can and will do if offered. These include short term help, practical, internships, apprenticeships, and other kinds of support and learning operations that also help refugees to assimilate, learn technical terms, and get to know the work culture in a particular society or particular trade or craft.

Our experience in the town of Borken shows that the young men there appreciate work of any kind, even if the additional amount of money is minor. Being needed, doing something useful, and learning a trade are in themselves of value; work experience is also considered to help in attaining asylum status. In the Bayernkeller Restaurant and Hotel in Borken where twenty or so young men are living, having work or a job is considered very important, and if one of them can attend the university in a close by city, that already counts as great success. For regular work, the City of Borken takes a number of young refugees to work in their 'builder's yard and repair facility,' with outside park, garden, and streets work and repair operations. Some refugees also work in the private sector. One young man works in a painting shop, he proudly explained to us, and another works in a car repair shop, a job he had occupied in his home country. Another works as a kitchen helper in the Italian restaurant 'Dal Circulo.' More work needs to be done to create legally sanctioned work opportunities for refugees who do not have official asylum status.

Asylum application, approval, or denial by authorities

At the same time that refugees and Germans are addressing housing, work, and overall acclimatization issues, refugees must also apply for legal asylum if they wish to stay in Germany. Germany is not an immigration country; there are only two mechanisms through which 
migrants may apply for legal residency in the country. First, Article 16a of Germany's 1949 Constitution includes provisions for asylum seekers (Basic Law for the Federal Republic of Germany, 2017). Second, federal law includes an "exception" policy, which states that the country does not allow immigration, except as appealed on a case by case basis (for example, for people who have married German citizens, for those with special work in Germany, etc.) (Federal Ministry of the Interior, 2017 and Scherer, 2016). Refugees apply for legal status through the asylum law. Asylum application processing can take from a few months to over a year. During the interim period between their arrival and the asylum decisions, refugees' are very limited in their abilities to find self-rented permanent housing and paid employment.

Asylum denials may be appealed, but the appeals process again can go on for many months to a few years. Asylum has recently primarily been approved for people from Syria, Iran, Iraq, and Eritrea, while the many others from places like Afghanistan, Pakistan, and Ethiopia and other African countries are denied. Asylum denials are increasing now that a few years have passed since the first large waves of refugees arrived, and growing numbers of people are now in precarious positions as migrants without legal status in Germany and Europe, but who are also not able to return to their home countries. This poses a serious dilemma for many of the refugees after so many days, weeks and even years of hardship.

\section{Findings and evaluation: The Wilkommen Kultur and its reality on the ground}

Our initial research into these three towns and five major topics for refugees focused on mapping the general situation facing these communities as a precursor to more targeted and extensive research. These first visits allowed us to collect material for our initial field study cases that helped us to find research supported answers to our questions and enough data to actually accomplish some evaluations with regard to our main question of how the implied promise of the is working on the ground.
Finding 1: Help and support structure are seemingly working well, but are also becoming overwhelmed by ever increasing refugee numbers in 2015-2016.

The support structure in the three German communities we investigated seemed to be quite well organized at the administrative, public, religious, and institutional levels, at the private business level, and also at the level of private initiatives. Overall, at all levels and in each community, we encountered a generous attitude and desire to help. The overall helping attitude can be seen as a positive sign of the refugee Wilkommen Kultur. For example, when refugees began to arrive in Borken, the Free Protestant Church there soon established a place and time for refugees and locals to meet every Monday for coffee and cake to just see each other, talk about issues and problems, but also just enjoy. They call this event and space Cafe Hope. Tomo Furukawazono participated in the Cafe Hope events on various occasions. In the City of Essen, Pastor Achim Gerhard-Kemper represents one of numerous neighborhood 'Round Tables' (Essen City Website, 2017b), public stakeholder meetings where refugee issues and how to live together with refugees could be discussed in an open and constructive manner.

However, in 2016, as more and more refugees reached even the smallest villages in Germany, city officials and residents started to wonder how they could actually handle and help more and more incoming refugees. Mr. Rolf Waldeck, the head of the City of Borken ad-hoc committee on refugees, was quite confident that with a number of about 100 refugees in the town he and volunteers could handle this crisis. But when the number became more than 200 refugees for a town of 13,500 inhabitants, Mr. Waldeck reported that he started to wonder how they could continue to successfully support the refugees.

Mr. Waldeck's worried sentiment also reflected the national opinion at the time, that the ever increasing magnitude of the refugee situation started to be seen as more and more difficult. As time goes on and the numbers 
of refugees grow, the Wilkommen Kultur is facing its first major tests locally, as well as nationally.

Finding 2: Refugee housing is a test of Wilkommen Kultur.

A.Housing is obviously a key element in the care for refugees. And while Germany was remarkably well prepared for taking care of refugee housing, the large number of refugees more often than not created serious accommodation challenges at the local level. While refugees are first housed in large federal arrival camps, it is really the local level where refugees are housed more long term and in a more open and connected way to the local community.

B.While the general tendency in Germany is to provide housing for refugees in existing building stock structures, there are also a limited number of new building structures provided for refugee housing. The unwritten policy is to provide the same kind of low cost housing for refugees and local citizens alike so that there is no indication of special, preferential treatment of refugees. In order to test more options, one of our architectural design studios took up a live-work design exercise at the edge of the central city in Essen and the University of Duisburg-Essen to explore socio-economic integration. Professor Howard Davis carried out a successful livework design studio for Syrian refugees in the winter quarter of 2017 at the University of Oregon, Department of Architecture in Eugene (CIU, 2017) (Illustration 6). This project raises the progressive question of next steps through which housing and work can help together with socio-economic integration.

Finding 3: Acclimatization requires communication; the mobile phone is key.

Daily life for refugees and how they become accustomed to their new surroundings includes a large area of practical matters, from learning a language, health issues, to connecting with the local community and keeping connections to family and friends in their home countries and cities.

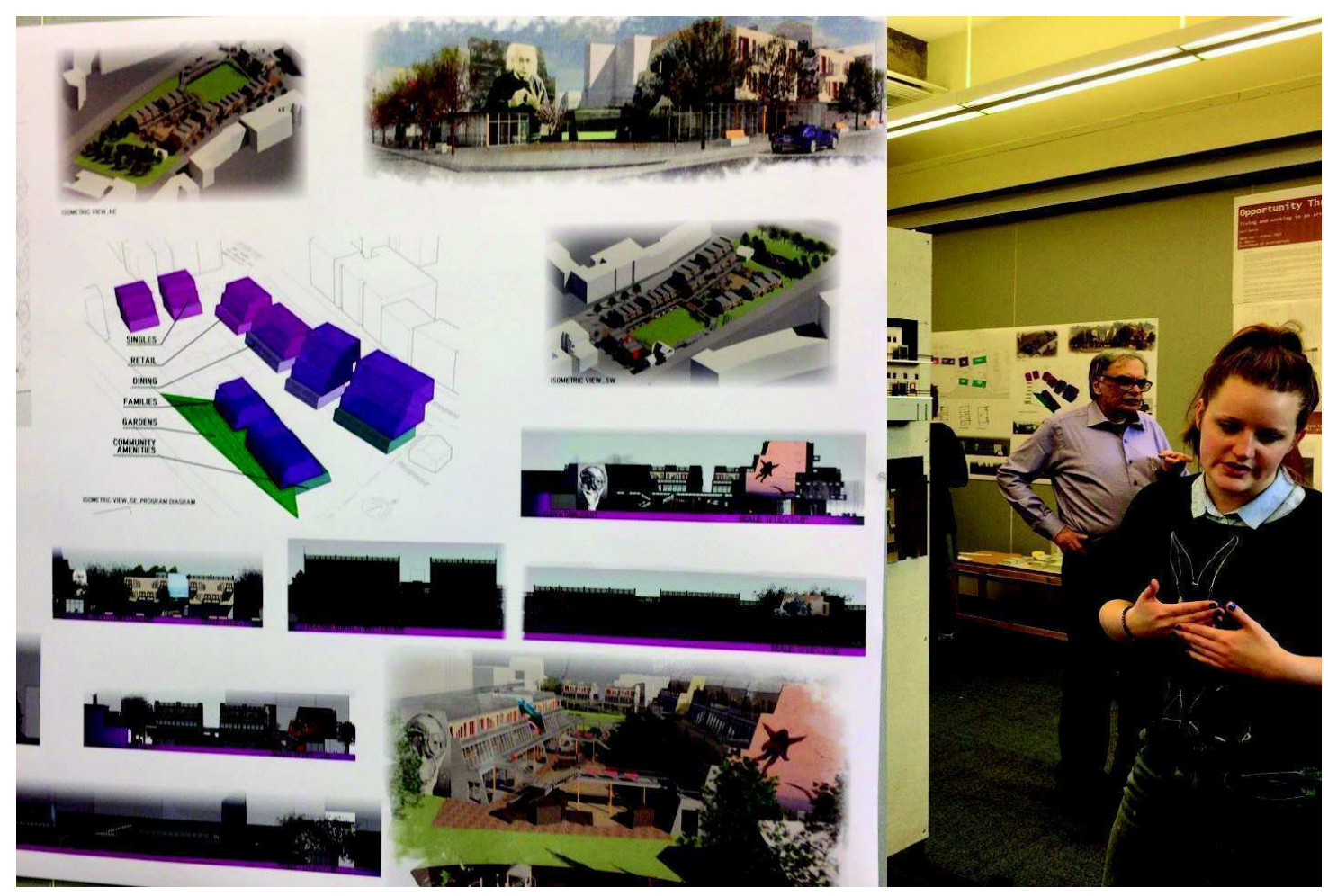

Figure 6.

'Refugee Live-Work Design Studio in the cities of Essen (Germany) and Portland (USA)' by Prof. Howard Davis, University of Oregon, Architecture Department, Winter 2017. 
A.Starting with the last first, almost every refugee has a cell phone, first for the purpose for staying in touch at home, and also for staying in touch with fellow refugees locally and in other cities in Germany or other EU countries. Smart phones and internet connection are critical tools for refugees to navigate new communities, to learn the language, and to keep up to date on their paperwork and asylum application process.

B.One of the key challenges concerning communication among refugees and citizens is that it can be difficult to commit to the level of investment required for teaching and learning a new language while it is still uncertain if refugees will be able or wish to stay in the country. Another challenge is that refugees are often coping with high amounts of stress, so it may be difficult to encourage social interaction with the pressure of learning a new language.

Finding 4: Work experience is critical for assimilation and integration, but it is difficult to get during asylum processing.

Next to housing, work is the biggest issue for refugees in terms of a regular daily life and in terms of security and outlook for a good economic future. One could say that refugees are taken care of quite well in terms of housing, health care, monetary support and other needs for daily life. In terms of work there are also a number of measures that are taken in cities and towns, such as internships, practica, and job learning, in the public as well as in the private sector. However, these activities or small jobs are not regular jobs with standard pay, insurance, and other benefits, the most important being retirement. Even for refugees with recognized asylum status there is no definite right on work with benefits. Here the promise that Chancellor Merkel made is incomplete in its results.

The welcoming invitation for refugees needs to include provision of regular jobs and support for private start-up enterprises by refugees. Socio-economic assimilation and especially integration depend largely on working opportunities in all kinds of forms, including self-help, start-ups (i.e., food related jobs), and regular paid jobs. In this area, a lot of work needs to be done to successfully help refugees become part of German society.

Finding 5: The asylum law and the German residence law are not sufficient to deal with the refugee crisis in an effective way.

One of the main reasons for a number of the difficulties and complications with refugees being fully welcome in Germany is the current legal structure regarding foreigners from outside the European Union. The two laws dealing with foreigners are the asylum law and the residence law. The asylum law gives one the right to apply for asylum and be provided for until a decision has been determined about refugee status. The residence law essentially states that non-citizens cannot live in Germany unless there are strong reasons for doing so. In a way, the United States is better able to receive refugees quickly due to the existence of immigration laws there that allow for quicker processing of applications.

Special laws need to be introduced in Germany to solve some of the problems for refugees including the right for more work opportunities or, even better, a solid comprehensive immigration law should be established by the parliament in order to provide more options for refugees to participate and become part of the host society in a faster, less troublesome, and productive way.

\section{Final comments: Outlook - One cycle complete}

With regard to our main question of direct or implied promises of the arrival city, best expressed by chancellor Merkel's invitation to all refugees to come to Germany, we can say that German society was surprisingly well prepared for taking on the challenge, especially on the local level of towns, cities, and villages. In the city of Borken, county of Kassel, and city of Essen, the administrations, as well as public and private organizations, and private citizens alike were managing various challenges quite well, such as housing, connections to refugees, providing work related opportunities, as well as 
helping with asylum matters, helping refugees to learn the language and so on. Refugees we were in contact with were well taken care of and reacted quite positively, on the one hand. On the other hand, when the numbers of refugees started to become larger and larger up to one million arrivals in 2015 alone, the general mood in the German population did swing with negative tendencies.

The choice of the three German cities was determined by specific criteria including size and scale differences, as well as availability and our own connections to universities and municipalities. However, in a discussion with Mr. Claus Muller from the renowned newspaper Frankfurter Allgemeine, Mr. Muller correctly pointed out that all our case study cities are located in western Germany, and none is in eastern Germany, where conditions are dramatically different. Consequently, and on the suggestion of Professor Ralf Weber from the Technical University of Dresden, we have decided to look at the city of Bautzen, close to the Polish border and the city of Dresden, to get a more complete picture in a more difficult context. We intend to tackle this task in the summer and fall of 2017.

The fact that our case study cities can be evaluated quite positively with regard to our main question of fulfilling the promises of the arrival city and Wilkommen Kultur on the ground is of course in itself remarkable as a positive result, and one can applaud the participating actors and organizations. However, people from other countries and around the world may also ask questions about all the negative news of hate crimes, attacks on refugee shelters with fire bombs and other nasty events that have taken place. For instance, one disturbing event occurred inside the county of Kassel at a former airport, where a large number of refugees from different ethnic backgrounds had a huge fight among themselves in the dining hall, which was reported all over the world (Deutsche Welle, 2015). We must note that this large camp is a national federal camp, not part of the responsibility of the county.

Finally, since early 2017, we hear and read more and more about young refugees who were not accepted with refugee status, but were rejected and in fact deported by police cordoned airplanes to their home countries such as Pakistan, Afghanistan, and African countries (Al Jazeera English, 2017). For example, during Dr. Neis' December 2016 visit to Borken he found out that Tahir, one of the Pakistan refugees with whom he had met the previous summer, had received notice that his asylum application had been rejected and had fled to another part of Europe to avoid deportation. This latest development in the refugee saga reminds us of the incomplete attempt for a better world. One refugee cycle has been completed with forced return to where these young men had started their difficult journey, but now they have nothing to show at home that was worth the effort (Süddeutsche Zeitung, 2017). For others who were accepted as asylants, a major step forward was achieved that continues to promise more success and start of a new life in the arrival city.

In this paper we discussed the results of initial research in three German communities, conducted primarily during August 2016. While much remains to be investigated, our visits and interviews provided insights into the five major topics summarized above and for preliminary findings. In our next step we would like to continue to explore and also confirm our findings and extend the scope of our field study work to other cities and challenging topics.

\section{References}

Al Jazeera English (2017), 'Rejected from Germany: One Afghan's story' (http://www.aljazeera.com/indepth/ features/2017/05/rejected-germany-afghanstory-170524152713481.html) accessed 8 June 2017.

Basic Law for the Federal Republic of Germany (2017), Bundesministerium der Justiz und für Verbraucherschutz (https:// www.gesetze-im-internet.de/englisch_gg/ englisch gg.html) accessed 8 June 2017.

Borken City Website (2017), Borken, (http:// www.borken-hessen.de/cms/Home/) accessed 19 May 2017

Bundesamt für Migration und Flüchtlinge (BAMF) Glossary (2017), Glossary - E EASY, (http://www.bamf.de/EN/Service/ 
Left/Glossary/ function/glossar.html?nn $=1449076 \& \operatorname{lv} 2=5832426 \& \operatorname{lv} 3=1504234$ ) accessed 2 May 2017.

Collaborative for Inclusive Urbanism(CIU) (2017), (http://www.inclusiveurbanism. org/) accessed 8 June 2017.

Der Westen (2015), 'Übersicht aller AsylUnterkünfte in Essen' (https://www. derwesten.de/staedte/essen/uebersicht-allerasyl-unterkuenfte-in-essen-id11076960. html) accessed 8 June 2017.

Deutsche Welle (2015), 'Clashes at KasselCalden migrant center in northern Germany leave several injured', (http://www.dw.com/ en/clashes-at-kassel-calden-migrantcenter-in-northern-germany-leave-severalinjured/a-18745007) accessed 7 June 2017.

Essen City Website (2017a), Flüchtlinge in Essen, (https://www.essen.de/leben/ fluechtlinge_1/fluechtlinge_in_essen.de.jsp) accessed 19 May 2017.

Essen City Website (2017b), Runde Tisch, (https://www.essen.de/leben/fluechtlinge_1/ runde_tische.de.html) accessed 8 June 2017.

Federal Ministry of the Interior (2017), Ayslum and Refugee Policy in Germany, (http:// www.bmi.bund.de/EN/Topics/MigrationIntegration/Asylum-Refugee-Protection/ Asylum-Refugee-Protection_Germany/ asylum-refugee-policy-germany_node. html) accessed 8 June 2017.

Kassel County Website (2017), Flüchtlingshilfe im Landkreis, (http://www.landkreiskassel. de/cms09/bildung/fluechtlingshilfeLKKS/) accessed 19 May 2017

PUARL International Conference (2016), (https://blogs.uoregon.edu/puar12016/) accessed 9 June 2017.

PUARL Refugee Research Websites (2017), Portland Urban Architecture Research Laboratory (PUARL), Refugee Integration in Europe: Pattern Language, Design and Buildings, (https://refugee.uoregon.edu/) accessed 25 May 2017.

Reddit (2017), How much money do refugees get in germany?, (https://www.reddit. com/r/europe/comments/3jcrmx/on_the topichow_much_money_do_refugees_get_ in/) accessed 8 June 2017.

Saunders, D. (2012) Arrival city: how the largest migration in history is reshaping our world (Vintage Books, New York).

Scherer, S. (Head of Youth Health and Education of Kassel County) (2016). Lecture about German asylum policy on 1 August, 2016.

Schmal, P. C., Elser, O., and Scheuermann, A. (ed.) (2016) Making Heimat (Hatje Cantz, Berlin)

United Nations, Department of Economic and Social Affairs, Population Division (2015). Trends in International Migrant Stock: The 2015 Revision. (United Nations database, POP/DB/MIG/Stock/Rev.2015).

UN High Commissioner for Refugees (UNHCR) (2016), Overview on UNHCR's operations Regional update - Europe, 28 September 2016, (http://www.refworld. org/docid/57f25a734.html) accessed 8 June 2017.

UN High Commissioner for Refugees (UNHCR) (2017). Figures at a Glance (http://www.unhcr.org/en-us/figures-at-aglance.html) accessed 8 June 2017.

Sommerpressekonferenz von Bundeskanzlerin Merkel (2015, August 31), Thema: Aktuelle Themen der Innen- und Außenpolitik, (https://www. bundesregierung.de/Content/DE/Mitschrift/ Pressekonferenzen/2015/08/2015-08-31pk-merkel.html) accessed 7 June 2017.

Süddeutsche Zeitung (2017), 'Abgeschoben nach Afghanistan' (http://gfx.sueddeutsche. de/apps/e359324/www/) accessed 22 May 2017.

Wehling, H., Schmidt, A., Pozo, R., Casanova, M., Pahlen, B., and Kürzdörfer, C. (2015). 'Inclusive neighbourhoods: Refugees in Essen, new challenges for community building, Cases studies: Altenbergshof (Nordviertel), Mathias-Stinnes Stadion (Karnap), Planckstrasse 42 (Holsterhausen), Hülsenbruchstraße (Altenessen) and Bamlerstrasse (Erbslöhstrasse)', DuisburgEssen University ARUS doctoral program, Winter Semester 2015/2016, Seminar. 